\title{
Current Status and Perspectives for the Estimation of Crop Water Requirements from Earth Observation
}

\author{
Guido D'Urso* \\ Dipartimento di Ingegneria Agraria e Agronomia del Territorio, Università di Napoli "Federico II" \\ Via Università 100, 80055 Portici (NA), Italy
}

Received: 13 January 2009. Accepted: 28 September 2009.

\begin{abstract}
This paper presents an overview of current techniques and recent developments in the application of Earth Observation data for assessing crop water requirements. During recent years there has been much progress in understanding land surface-atmosphere processes and their parameterisation in the management of land and water resources. This knowledge can be combined with the potentiality of Earth Observation techniques from space, which are able to provide detailed information for monitoring agricultural systems.

As today, two main developments in the field of Earth Observation data acquisition and analysis have occurred:

a) availability of new generations of sensors, with enhanced spectral and spatial resolution;

b) detailed knowledge of the processes that determine the response of land surface as detected from remote sensors in different regions of the electromagnetic spectrum.

These advancements have made possible a "quantitative" approach in the interpretation of Earth Observation data, ready for being transferred to operative applications i.e. for irrigation scheduling and water management. This paper presents a review of current applications of optical data in the visible and near infrared spectral regions, with particular emphasis to the experiences developed by the author within AQUATER and other research projects project.
\end{abstract}

Key-words: irrigation, crop water requirements, evapotranspiration, satellites remote sensing.

\section{Introduction}

The assessment of crop water requirements (CWR) is an essential information for the management of water resources, especially in arid and semi-arid regions where irrigation represents the largest consumer of water. Environmental, micro-meteorological and hydrological models are widely available for a calculation of crop water requirements at field scale. Simulation models of soil water flow have been validated in different environments (Feddes et al., 1988; Santini, 1992) and they may provide quantitative information about water balance terms of particular relevance, i.e. the recharge of aquifers and the evaporation from vegetated surfaces.

Information about the spatial and temporal variability of CWR is not only useful for a better understanding of hydrological processes but also for implementing more efficient irrigation distribution criteria at both farm and district levels.

A paradigmatic example is represented by the management in the Italian Consortia of Land Reclamation and Irrigation (state-controlled associations of farmers), which are responsible for the distribution of water resources for agricultural use in an efficient and equitable way. In most cases, even in presence of metered distribution networks, the water allocation (and the application of corresponding fees) is done on the basis of the extension of irrigated area and not of water volumes. As a consequence, farmers are not motivated to adopt efficient water saving strategies, which results in generalised over-irrigation and misuses of water resources. The availability of reliable, objective and timely information about crop water requirements 
allows the implementations of efficient water distribution criteria based on the actual irrigation needs of crops.

Satellite observations of the Earth surface in different regions of the electromagnetic spectrum have been used for about three decades to monitor land surface patterns. The potentiality of Earth Observation techniques in the management of land and water resources has been widely acknowledged (FAO, 1995; Schultz et al., 2000). The repeatability of observations on a cyclic basis and the availability of high spatial resolution multispectral data - which are com- mon characteristic to the Landsat and SPOT satellites - are particularly suitable for mapping crops and irrigated areas with satisfactory accuracy and in a cost-effective way. During recent years, the amount of available sensors, with enhanced observation capabilities, has increased enormously the possibilities of acquisition. The spatial resolution is one order of magnitude better than the Landsat TM, at an even more decreasing cost per unit area. A non-exhaustive list of currently available systems for different spectral regions is given in Tables 1a-c. On this baseline, many operative applications have been de-

Table 1a. Multispectral Earth Observation systems - Visible and Near Infrared wavelengths.

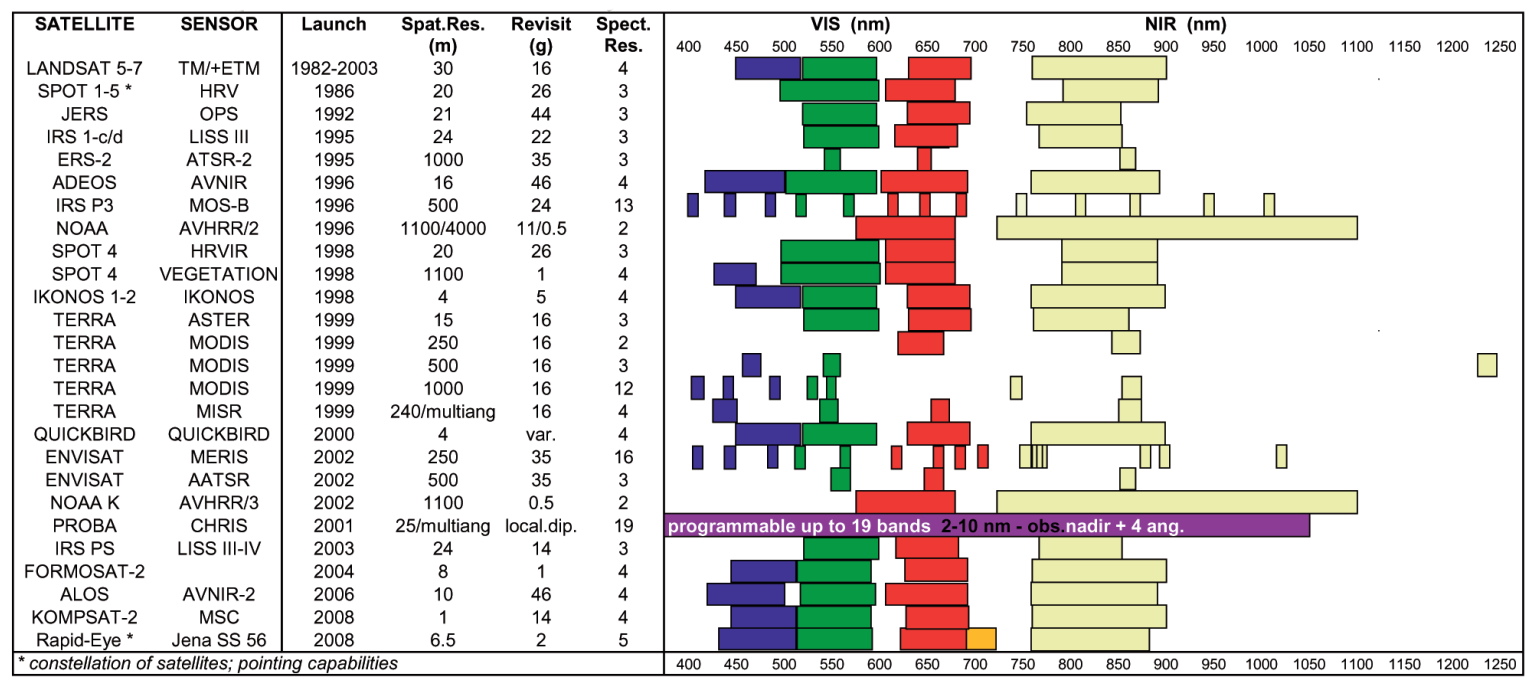

Table 1b. Multispectral Earth Observation systems - Shortwave Infrared wavelengths.

\begin{tabular}{|c|c|c|c|c|c|c|c|c|c|c|c|c|c|c|c|c|c|c|}
\hline \multirow[t]{2}{*}{ SATELLITE } & \multirow[t]{2}{*}{ SENSOR } & \multirow[t]{2}{*}{ Launch } & \multirow{2}{*}{$\begin{array}{l}\text { Spat.Res. } \\
\text { (m) }\end{array}$} & \multirow{2}{*}{$\begin{array}{c}\text { Revisit S } \\
\text { (g) }\end{array}$} & \multirow{2}{*}{$\begin{array}{l}\text { Spect. } \\
\text { Res. }\end{array}$} & \multirow[b]{2}{*}{1300} & \multirow[b]{2}{*}{1400} & \multicolumn{11}{|c|}{ SWIR (nm) } \\
\hline & & & & & & & & 1500 & 1600 & 1700 & 1800 & 1900 & 2000 & 2100 & 2200 & 2300 & 2400 & 2500 \\
\hline LANDSAT 5-7 & TM/+ETM & 1982-2003 & 30 & 16 & & & & & & & & & & & & & & \\
\hline JERS & OPS & 1992 & 21 & 44 & 4 & & & & & & & & & & & & & \\
\hline IRS 1c & LISS III & 1995 & 71 & 22 & 1 & & & & & & & & & & & & & \\
\hline ERS-2 & ATSR-2 & 1995 & 1000 & 35 & 1 & & & & & & & & & & & & & \\
\hline IRS P3 & MOS & 1996 & 500 & 24 & 1 & & & & & & & & & & & & & \\
\hline SPOT $4-5$ * & HRVIR & 1998 & 20 & 26 & 1 & & & & & & & & & & & & & \\
\hline SPOT 4 -5* & VEGETATION & 1998 & 1100 & 1 & 1 & & & & & & & & & & & & & \\
\hline TERRA & ASTER & 1999 & 30 & 16 & 6 & & & & & & & & & & & & & \\
\hline TERRA & MODIS & 1999 & 500 & 16 & 2 & & & & & & & & & & & & & \\
\hline TERRA & MODIS & 1999 & 1000 & 16 & 1 & & $\square$ & & & & & & & & & & & \\
\hline ENVISAT & AATSR & 2002 & 1000 & 35 & 1 & & & & & & & & & & & & & \\
\hline NOAA K & AVHRR/3 & 2002 & 1100 & 0.5 & 1 & & & & & & & & & & & & & \\
\hline \multicolumn{6}{|c|}{ "constellation of satellites; pointing capabilities } & 1300 & 1400 & 1500 & 1600 & 1700 & 1800 & 1900 & 2000 & 2100 & 2200 & 2300 & 2400 & 2500 \\
\hline
\end{tabular}

Table 1c. Multispectral Earth Observation systems - Thermal Infrared wavelengths.

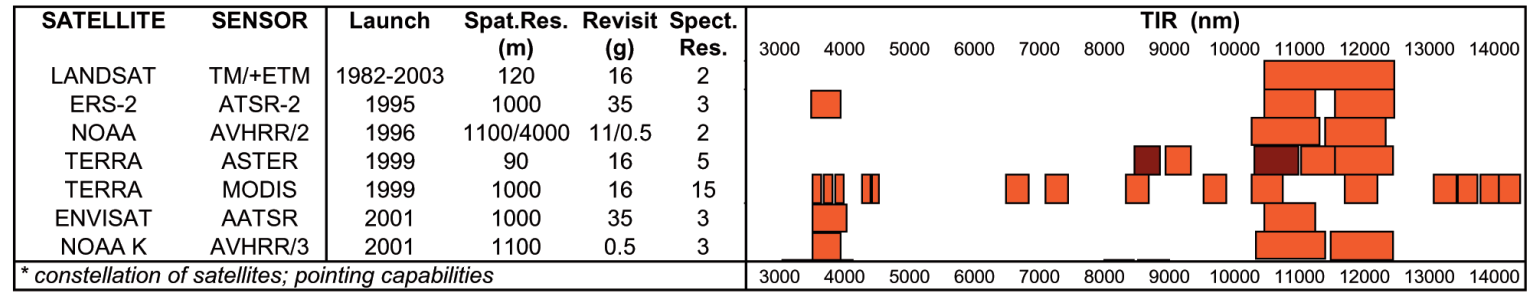


veloped and tested for supporting irrigation water management, thanks also to the impressive progresses in the field of Information and Communication Technologies (ICT). Nowadays satellite images are delivered via Internet within few hours from the acquisition time, and they can be quickly processed to get final-users products distributed in near-real time.

The purpose of the present work is to highlight the "main streams" of Earth Observation applications in this field, by considering among others - the experiences carried out by the author in the context of AQUATER research project (http://aquater.entecra.it).

\section{Background concepts and definitions for the estimation of crop water requirements}

Accordingly to the definition of ICID (2000), the crop water requirement (CWR) represents the "total water needed for evapotranspiration, from planting to harvest for a given crop in a specific climate regime, when adequate soil water is maintained by rainfall and/or irrigation so that it does not limit plant growth and crop yield". This definition corresponds to the so-called "standard conditions" introduced by the wellknow F.A.O.-56 procedure of Allen et al. (1998) for the calculation of potential evapotranspiration, $E T_{p}$ which is the main term in the following relationship commonly used to compute CWR:

$$
C W R=E T_{p}-P_{n}
$$

where $P_{n}$ represents the precipitation net of foliage interception. The F.A.O.-56 procedure, which is the evolution of the original methodology proposed by Doorenbos and Pruitt in 1977, is based on the schematisation of Monteith (1990). The evapotranspiration rate of $a$ canopy is calculated by means of a physical model describing the exchange of mass and energy between the canopy and the atmosphere and requiring, besides the climatic data, the characteristics of the canopy, namely the Leaf Area Index, $L A I$, the surface albedo, $\alpha$, the crop height $h_{c}$ and the canopy resistance $r_{c}$. This latter term is dependent on the crop physiology, plus climatic and hydrological conditions, i.e. incoming solar radiation, vapour pressure deficit and soil water status. Under standard or poten- tial conditions, as defined above, i.e. when soil water is not limited, the canopy resistance reaches a minimum value $r_{c, \text { min }}$ that can be estimated using the expression (Szeicz and Long, 1969; Jensen et al., 1990):

$$
r_{c, \min }=\frac{r_{\text {leaf } \min }}{L A I_{\text {eff }}}
$$

In Eq. (2) $r_{\text {leaf,min }}$ is the minimum stomatal resistance of a single leaf, approximately equal to $100 \mathrm{~s} \mathrm{~m}^{-1}$, and $L A I_{\text {eff }}$ is the fraction of leaf area index $L A I$ effectively taking part in the evapotranspiration process. It is common to take $L A I_{\text {eff }}=L A I$ until the value of $0.5 L A I_{\text {max }}$ is reached, after which $L A I_{e f f}$ is kept constant. Kelliher et al. (1995) showed that a minimum value $r_{c, \text { min }}=50$ to $70 \mathrm{~s} \mathrm{~m}^{-1}$ applies to most crops hence the relationship is valid for $L A I=4$. For larger values of $L A I$, a constant $r_{c \text {, min }}$ is taken. As such, the evapotranspiration under standard conditions $E T_{p}$ is a function of meteorological variables (incoming solar radiation, air temperature and humidity, wind speed) and canopy parameters $\left(L A I, \alpha\right.$ and $\left.h_{c}\right)$.

The equation to calculate $E T_{p}$ from these data is also referred to as the direct calculation of the F.A.O.-56 procedure (http://www.fao.org/ docrep/X0490E/X0490E00.htm), to which we refer for further analytical details.

For canopies not covering completely the soil surface, we need to distinguish between soil evaporation and canopy transpiration. The potential soil evaporation rate $E_{s, p}$ can be estimated from $E T_{p}$ as a function of $L A I$ :

$$
E_{s, p}=E T_{p} e^{-c L A I}
$$

where $c$ is an extinction coefficient. This relationship is in agreement with the approach suggested by Ritchie (1972), which is based on the extinction of net radiation as an exponential function of LAI. Then, the potential transpiration rate $T_{p}$ is derived as the residual term between potential evapotranspiration and soil evaporation rates:

$$
T_{p}=E T_{p}-E_{s, p}
$$

It is important to remember that the parameter $L A I$ is also needed to calculate the net 
precipitation $P_{n}$ in Eq. (1) from rain-gauge data (Braden, 1985). The difficulties related with the measurement of the set of canopy parameters $\left(L A I, \alpha\right.$ and $\left.h_{c}\right)$ have determined the recurrent usage of the "old" crop coefficient concept, introduced by Doorenbos and Pruitt (1977). The value of crop coefficient $K_{c}$ is commonly attributed from a field evaluation of the crop development and phenological stage by using the tables proposed by the original authors and also reported in the F.A.O.-56 procedure. It is clear that the crop coefficient $K_{c}$ is a proxy of the canopy parameters $\left(L A I, \alpha\right.$ and $\left.h_{c}\right)$; indeed, an analytical expression relating $K_{c}$ to climatic data and canopy parameters can be easily found by means of a direct calculation procedure (Stanghellini et al., 1990).

It is interesting to notice that the same canopy parameters entering the direct calculation of $E T_{p}$ are also influencing to a great extent the spectral response of a cropped surface, i.e. the way it appears from a remote sensor in the visible and infrared wavelengths.

Given this background information, we will distinguish the following three different groups of methodologies for the utilisation of Earth Observation (E.O.) in the assessment of crop water requirements:

1. classification approaches;

2. vegetation index approach;

3. F.A.O.-56 analytical approach.

We need to clarify that the above definition of CWR does not include crop stress conditions due to limited soil water availability, which might be detected by using remote observations in the thermal range (Jackson et al., 1981; Bastiaanssen, 1995; Kustas et al., 1996). Although thermal remote sensing techniques have produced a better understanding of mass and energy exchanges in the soil-canopy-atmosphere continuum, their operational support in irrigation management is rather limited. With the end of Landsat era, the current spatial resolution of thermal imagers from space, with exclusion of ASTER (which is a research instrument), is too coarse ( $\cong 1 \mathrm{~km}-$ Tab. $1 \mathrm{c})$ for fragmented and heterogeneous cropping patterns. Airborne sensors appear more suitable for validation purposes of local studies, but the resulting costs of operation and processing are in most cases unacceptable for routine applications.

\section{Classification approaches}

Applications in agricultural water management date back to early developments of remote sensing from space. A first application in this field was the derivation of crop water requirements maps (Estes et al., 1978) by combining land-use maps obtained from classification of satellite images with tables of crop coefficients $K_{c}$ (Doorenbos and Pruitt, 1977). This approach, still used in some applications, has two main drawbacks: 1) an unique $K_{c}$ value is considered for each land-use or crop-type regardless of different phenological stages and growth conditions; 2) the intrinsic relationship between surface reflectance and canopy development is not utilised. The attribution of a unique crop coefficient $K_{c}$ to each field only on the basis of land cover or crop type information is rather questionable. This method does not achieve accurate results unless detailed information about planting date and actual canopy development in each mapping unit is available.

The $K_{c}$ value is not necessarily dependent on land use description or crop type, but it is strongly influenced by the spectral behaviour of observed surfaces. As such, crop coefficients values can be related to canopy development and fractional vegetation cover. Since these vegetation characteristics are well correlated with spectral reflectances, it is possible to establish a correlation between remote multispectral observations of uniformly growing crops and corresponding $K_{c}$-values derived from field investigations (Bausch and Neale, 1987; Choudhury et al., 1994). Accordingly with previous considerations, it is possible to formulate the hypothesis that crops or groups of crops with similar spectral behaviour have also the same $K_{c}$-value. As a consequence, different techniques can be found for the definition of the training sets to be used in a classification procedure of multispectral images (D’Urso and Menenti, 1996). However, this method has the disadvantage of a subjective a priori assignment of a $K_{c}$ value to each spectral class.

This type of classification approach has been tested in the past by using two Landsat TM images acquired in an irrigation district located in Mendoza, Argentina and more recently in the Campania Region, Italy (D'Urso, 2001). In this latter site, Leaf Area Index measurements were 
Table 2. Crop coefficient $K_{c}$, variance of $K_{c}$ clusters and separability index, $J M^{*}$, for the different sets of signatures:

- NO_clus: each spectral sample considered as a single signature;

- Kc6: grouping in 6 classes based on Kc-values attributed from field observations;

- BT4w6: non-hierarchical clustering applied to the reflectance values in bands TM3, 4 and 5;

- BT5r7: similarly to BT4w6, 7 with addition of bands TM 2 and 7;

- NH4m6: non-hierarchical clustering based on maximum Mahalanobis distance between groups, applied to data in bands TM3, 4 and 5;

- MD4c6: similarly to NH4m6, but clustering criterion based on minimum determinant of the sum-of-squares and product (SSP) matrix within groups.

\begin{tabular}{lcccccc}
\hline SET & NO_clus & Kc6 & BT4w6 & BT5r7 & NH4m6 & MD4c6 \\
\hline$K_{c}(1)$ & - & $<0.4$ & 0.412 & 0.412 & 0.533 & 0.467 \\
$K_{c}(2)$ & - & $0.4-0.6$ & 0.592 & 0.551 & 0.799 & 0.559 \\
$K_{c}(3)$ & - & $0.6-0.8$ & 0.813 & 0.777 & 0.801 & 0.818 \\
$K_{c}(4)$ & - & $0.8-0.9$ & 0.836 & 0.822 & 0.802 & 0.900 \\
$K_{c}(5)$ & - & $0.9-1.0$ & 0.924 & 0.839 & 0.805 & 0.956 \\
$K_{c}(6)$ & - & $>1.0$ & 1.004 & 0.939 & 0.858 & 0.981 \\
$K_{c}(7)$ & - & - & - & 1.004 & - & - \\
\hline $\operatorname{var}\left(K_{c}\right)$ & - & - & 0.049 & 0.040 & 0.014 & 0.047 \\
$J M^{*}$ & 0.956 & 0.600 & 0.838 & 0.859 & 0.645 & 0.766 \\
\hline
\end{tabular}

available in about 80 sites; for each one of these sites, a mean vector of spectral reflectance was extracted from atmospherically corrected images. Successively, a $K_{c}$-value was assigned to each site by using the tables of Doorenbos and Pruitt (1977). Cluster analysis has been performed on these reflectance vectors to define similarities between them. A combination of both hierarchical and non-hierarchical methods has been applied to produce six different sets of spectral signatures (Tab. 2).

Except for one cluster set (Kc6 in Tab. 2), the value of $K_{c}$ was not considered as a variable in the clustering, but it was successively calculated by averaging the values of the samples allocated to each class. Classes separability was then estimated by means of the Jeffrey-Matusita normalised distance $J M^{*}$. The analysis of Table 2 shows that the various clustering criteria lead to different $K_{c}$-values in each respective class. As expected, the highest separability applies to the non-clustered set NO-clus, where $J M^{*}=0.956$. The set BT4w6 gave the largest differentiation of $K_{c}$ - values among the 5 clustered sets, i.e. Kc6 through MD4c6 and it had the second-best separability. For all sets, the $J M^{*}$ values below the threshold of 0.88 imply a probability of classification errors greater than 0.10 ; in particular, a very unsatisfactory separability resulted for the sets Kc6 and NH4m6.

This second classification approach should be preferred to the traditional classification based on land-use mapping because it takes into account of differences in crop development and thus in the value of $K_{c}$. However, as shown by the given example, it is difficult to define the crop coefficient value but the method might be preferred when field measurement of canopy properties are not available. In such situations, reference values of crop coefficients $K_{c}$ might be assigned by using tables similar to those proposed by Doorembos et al. (1977) to the image pixels in the training set selected for the image classification.

\section{Vegetation index approach}

A more quantitative approach has been introduced with the application of vegetation indices, $V I$, from space measurements of canopy reflection (Deering, 1978). The typical reflective behavior of a vegetated surface and its strong dependence on the canopy development is shown in Figure 1. From this evidence, Tucker (1978) proposed to use the spectral regions of red wavelengths $(0.63-0.69 \mu \mathrm{m})$ and near infrared $(0.76-0.90 \mu \mathrm{m})$ to monitor the development of vegetation from satellites. Several vegetation indices have been defined as linear combinations of reflectance measurements in the two mentioned wavelength regions: from the simple ratio to the most widely used Normalized Difference Vegetation Index NDVI, calculated from the surface reflectance in the near-infrared $\rho_{N I R}$ and 


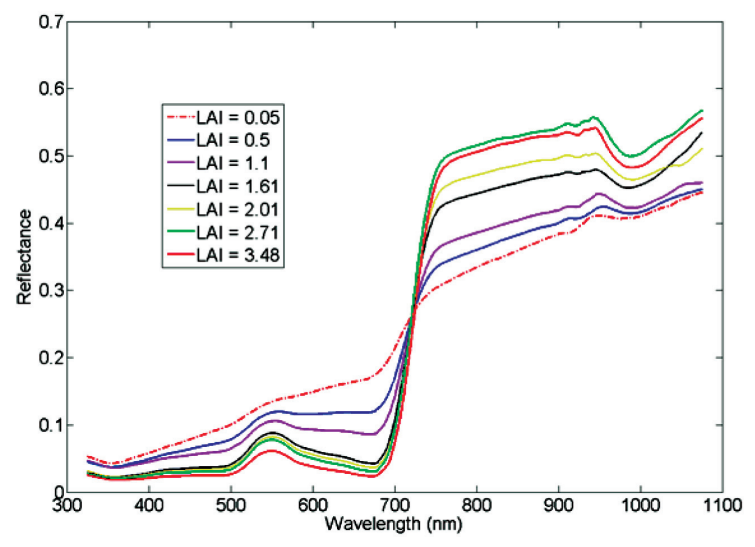

Figure 1. Spectral response of a canopy in the visible $(380-750 \mathrm{~nm})$ and near infrared (800-2500 $\mathrm{nm})$ regions; at increasing LAI, the reflectance in the near infrared increases, while in the red portion decreases $(680 \mathrm{~nm})$.

in the red band $\rho_{R}$, by means of the following relationship:

$$
N D V I=\frac{\rho_{N I R}-\rho_{R}}{\rho_{N I R}+\rho_{R}}
$$

In many applications, NDVI is calculated directly from the quantized radiance at the sensor (Digital Number), without including any calibration or radiometric correction. Several indices have been proposed as alternatives to NDVI, such the Perpendicular Vegetation Index PVI (Richardson et al., 1977), the Soil-Adjusted Vegetation Index SAVI (Huete, 1988), the Weighted Difference Vegetation Index WDVI (Clevers, 1989) and the Global Environment Monitoring Index GEMI (Pinty et al., 1992). These indices have been formulated in order to reduce the influence of perturbing effects such as the soil background or the atmospheric influence, which may alter significantly the reflectance of vegetated surfaces.

Until the mid 1990's a large number of agronomic applications has been developed, including the evaluation of crop water demand; these studies have been mostly based on the empirical relationships between NDVI (as well as other indices) and canopy development. This consideration is the baseline for investigating the direct correspondence between $K_{c}$ and vegetation indices. In particular, Bausch et al. (1987) established the potential for modelling crop coefficient as a function of the Near Difference Vegetation Index (NDVI) and used this ap- proach to perform irrigation scheduling of corn fields (Bausch; 1995; Choudhury et al., 1994). The $K_{c}$-NDVI relationship has been further explored by Calera et al. (2005) in the course of the EU-funded project DEMETER (http:// www.demeter-ec.net). On the basis of intensive multi-temporal acquisitions and simultaneous field evaluations, the following linear relationship has been defined to relate the basal crop coefficient $K_{c b}$, which is equivalent to $T_{p}$ in Eq. (4), and NDVI (D'Urso and Calera, 2006):

$$
K_{c b}=1.5625 N D V I-0.1
$$

Considering that the soil evaporation coefficient can also be directly related to the NDVI through the fractional vegetation cover $f_{c}$ (Calera et al., 2001), the following relationship for $K_{c}$-NDVI can be found:

$$
K_{c}=1.25 N D V I+0.2
$$

These equations have been derived by taking the minimum and maximum values reported in Table 3; these values are valid for NDVI calculated from E.O.-based surface reflectance and they are not crop-dependent. However, local calibration on specific crop types may improve to a great extent the accuracy of estimation of crop water requirements. The above relationships have been further tested in different environments within the experimental activities of the PLEIADeS project (http://www.pleiades.es).

The $K_{c}$-NDVI approach is simple and immediate; as such it is very suitable for operative real-time applications. On the other hand, this method has several critical points:

a) the relationship between $K_{c}$ and NDVI is based on subjective evaluations of crop development in the field, and as such can not be validated extensively on different types of crops (excluding well-maintained lysimeter installations);

b) the NDVI is very sensitive to atmospheric

Table 3. Maximum and minimum values of NDVI and derived parameters.

\begin{tabular}{lcccc}
\hline & $N D V I$ & $K_{c b}$ & $f_{c}$ & $K_{c}$ \\
\hline minimum & 0.16 & 0.15 & 0 & 0.4 \\
maximum & 0.80 & 1.15 & 0.8 & 1.2 \\
\hline
\end{tabular}


scattering and soil background; as such, several correction methods have been proposed in the literature, including alternative vegetation indices as earlier mentioned;

c) the NDVI of a vegetation cover is also very much dependent on the viewing angle. Deviation from a viewing angle larger than $20^{\circ}$ from nadir may result in an overestimation of NDVI;

d) the radiometric information of NDVI is very limited, and thus is not able to detect many surface patterns which may affect its reflectance behaviour.

\section{F.A.O.-56 analytical approach}

During recent years, there has been a consistent effort to estimate land surface parameters from Earth Observation data with special emphasis to LAI and albedo. These parameters can be estimated either by using empirical relationship with surface reflectance values either by means of inversion techniques in canopy radiative transfer models (Verhoef, 1984; Pinty et al., 1990; D'Urso et al., 2009a).

So doing, the main limitation in the direct calculation of $E T_{p}$ in the F.A.O.-56 procedure, i.e. the estimation of the required canopy parameters, can be eliminated by processing E.O. data to derive them. Within the AQUATER project, the F.A.O.-56 equation has been rearranged to be used directly with E.O.-based LAI and albedo values. The equation is derived by using a constant value for $h_{c}=0.40 \mathrm{~m}$, which is a valid assumption for conditions of high solar irradiance (typical summer condition in Mediterranean climate) and for LAI $>0.5$. By using daily meteorological data in typical summer conditions in Southern Italy, it has been evaluated that the assumption of a fixed crop height of $0.4 \mathrm{~m}$ produces an average error minor than $10 \%$ on $E T_{p}$. So doing, the calculation of $E T_{p}$ requires standard climatic data, LAI and surface albedo $\alpha$ :

$$
E T_{p}=\frac{86400}{\lambda}\left\{\frac{\Delta\left[R_{s}(1-\alpha)\left(1-0.4 e^{-0.5 L A I}\right)+L^{*}\right]+c_{p} \rho_{a}\left(e_{s}-e_{a}\right) U / 124}{\Delta+\gamma(1+U / 0.62 L A I)}\right\} \quad(\mathrm{mm} / \mathrm{d})
$$

In Eq. (8) $R_{s}$ is the incoming solar radiation $\left(\mathrm{Wm}^{-2}\right)$ and $U\left(\mathrm{~ms}^{-1}\right)$ the wind speed. The other variables, namely $L^{*}$ (net longwave radiation), $c_{p}$ (air specific heat), $\rho_{a}$ (air density), $\left(e_{s}-e_{a}\right)$ (vapour pressure deficit), $\lambda$ (latent heat of vaporisation of water), $\Delta$ (slope of saturated vapour pressure vs. temperature curve) and $\gamma$ (thermodynamic psychrometric constant) are calculated from measurements of air temperature $\left({ }^{\circ} \mathrm{C}\right)$ and relative humidity at a groundbased meteo station. Due to its initial assumption (fixed canopy height), Eq. (8) may require adaptations under different climatic conditions.

The average value of $E T_{p}$ resulting from the application of Eq. (8) for the second decade of July 2005 in the Sele Plain (Campania Region, Italy) for variable LAI and albedo is shown in the plot of Figure 2. We notice that the sensitivity of Eq. (8) to the value of LAI is greater than that of albedo; the maximum variation of $E T_{p}$ with albedo is less than $1 \mathrm{~mm} / \mathrm{d}$ and it decreases with LAI. Diversely, if we consider a variation of $\pm 0.5 \mathrm{LAI}$, we get an average variation of the $E T_{p}$ value of about $1 \mathrm{~mm} / \mathrm{d}$. On the basis of these considerations, Eq. (8) can be applied for the estimation of $E T_{p}$ in summer conditions with an accuracy of about $\pm 1 \mathrm{~mm} / \mathrm{d}$ if the albedo is known with an accuracy of \pm 0.05

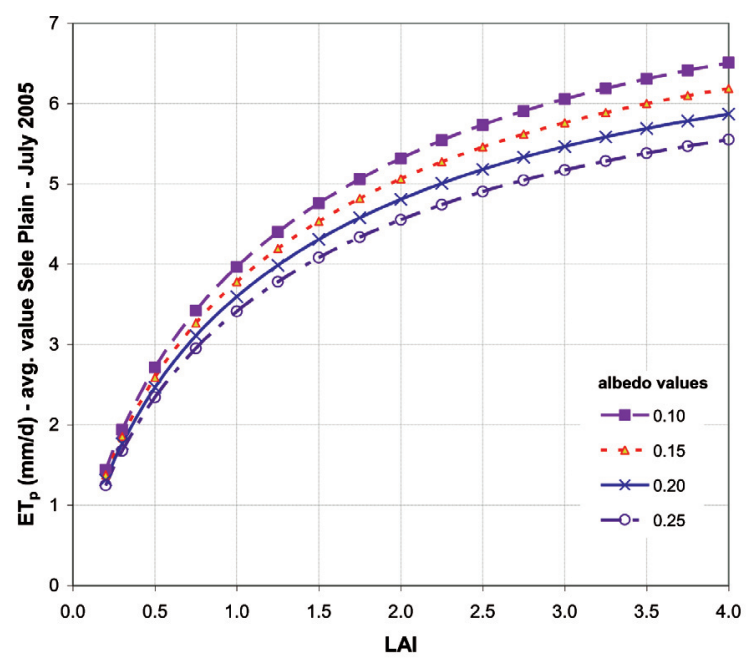

Figure 2. Sensitivity analysis of $E T_{p}$ with fixed $h_{c}(0.4$ $\mathrm{m})$ and variable albedo and LAI. The $E T_{p}$ value is calculated as the average over the second decade of July 2005. 
and the LAI with \pm 0.5 . The values of albedo and LAI within this accuracy limits can be derived from the analysis of E.O. data.

Simplified empirical methods are available to estimate surface albedo and Leaf Area Index from satellite-based surface reflectance with satisfactory accuracy for the application of Eq. (8). In these methods, LAI is derived by means of regression equations with different types of vegetation indices to reduce the atmospheric effects or the soil background influence. The canopy is generally assumed to behave as a Lambertian surface, thus the canopy reflectance is constant with the angle of observation. The accuracy of these expressions is confined within the validity of calibration of the regression used, which are often crop-dependent and sensor specific. Broad-band sensors in the visible and near-infrared, i.e. Landsat, SPOT, IRS, Terra-Aster, have been intensively used for deriving maps of $\alpha$ and LAI.

In the case of LAI, empirical approaches implicitly assume that all other factors, except LAI, influencing the spectral response of canopy are fixed and the following extinction function is used (Baret et al., 1991):

$$
V I=V I_{\infty}-\left(V I_{\infty}-V I_{s}\right) e^{-\beta^{\prime} L A I}
$$

Eq. (8) describes the variation of absorption and reflection of radiation in a canopy partially covering the soil. $V I_{s}$ is the value of a generic vegetation index for bare soil and $V I_{\infty}$ for a full vegetation cover; the parameter $\beta$ ' is an empirical coefficient, corresponding to the increase of $V I$ for an unitary increase of LAI. On this baseline, Clevers (1989) has proposed a quite robust method, based on the Weighted Difference Vegetation Index (WDVI) defined as follows:

$$
W D V I=\rho_{N I R}-\rho_{R} \frac{\rho_{N I R, S}}{\rho_{R, S}}
$$

where the subscript $\mathrm{s}$ is referred to bare soil conditions. The ratio of near-infrared and red soil reflectance is also known in the literature as the "soil line slope", and it can be derived by analysing a scatterplot of bare soil pixels identified within the image; its value is generally close to 1 . Finally, the LAI is related to WDVI of the observed surface through the expression:

$$
L A I=-\frac{1}{A} * \ln \left(L-\frac{W D V I}{W D V I_{\infty}}\right)
$$

In Eq. (11), $A^{*}$ is an extinction coefficient, similarly to $\beta$ ' in Eq. (9), to be determined from simultaneous measurements of $L A I$ and WDVI; $W D V I_{\infty}$ is the asymptotical value of $W D V I$ for $L A I \rightarrow \infty$. A similar relationship has been derived by Price (1992). This approach has been validated by means of numerical models simulating the reflectance of leaf and canopy in a wide range of conditions. These models confirmed that an accurate estimate of $L A I$ requires the knowledge of the leaf angle distribution, and, to a minor extent, of other factors, such as sun-zenith angle, chlorophyll content and mesophyl structure.

Within the AQUATER project an extensive validation of the empirical parameter $A^{*}$ has been carried out in the Sele plain, thus giving the possibility of LAI retrieval with sufficient accuracy for the application of Eq. (8). The scatterplot in the Figure 3 shows the strong correlation between LAI values measured in the field by using the portable canopy analyser LAI-2000 Licor and the corresponding estimates made from Landsat images contemporary to the ground measurements. The analysis of the scatterplot evidence that the retrieval accuracy is good for LAI $<3$; this is mainly due to the wellknown saturation effect typical of all vegetation indices. The resulting RMSE is 0.47 over the considered range of LAI values. The mentioned saturation effect is not particularly relevant for the application of Eq. (8) to estimate crop water requirements, since the sensitivity to LAI decreases which exhibit an asymptotical behaviour for LAI > 3 (Fig. 2). Diversely, when we are interested in precise biomass evaluations or in forestry studies, the empirical approach may result inappropriate. However, the estimation of LAI is not only useful for crop water requirements but also in other agronomic applications; i.e. in the context of AQUATER a scheme for assimilating E.O.-based LAI estimates into crop growth models has been experienced with success (Acutis et al., 2010).

In case we need to explicitly consider the crop height $h_{c}$ in the calculation of $E T_{p}$ by using the complete F.A.O.-56 equation, an empirical relationship between LAI and $h_{c}$ can be easily defined for each crop type. A more physically-based approach has been tried out by Menenti and Ritchie (1994), by using airborne laser altimeter data for profiling the surface el- 
soil line slope $=1,115-\mathrm{WDVI}_{\mathrm{inf}}=0,55-A^{*}=0,33$

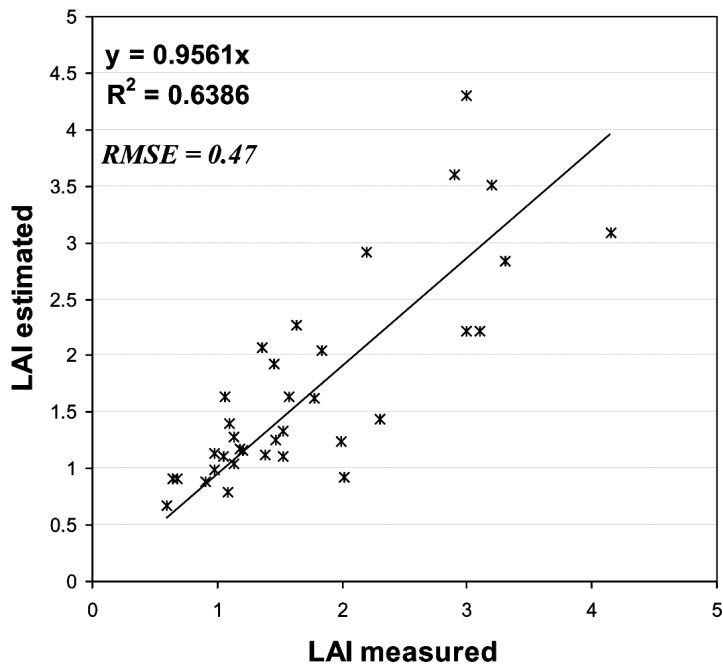

Figure 3. Calibration of Eq. for the Sele plain, data taken during the field campaign for the AQUATER projects on different types of crops.

evation; at present, however, this technique, can not be considered as applicable on a routine basis.

The estimation of surface albedo can be done by using a simplified form of its physical definition. By invoking the Lambertian assumption again, the spectral integration of surface reflected radiance $\mathrm{K}^{\uparrow}$ is approximated in discrete form as follows:

$$
\alpha=\pi \int_{0}^{\infty} \frac{K^{\uparrow}(\lambda)}{K^{\downarrow}(\lambda)} d \lambda \cong \pi \sum_{\lambda_{1}}^{\lambda_{n}} \frac{K_{\lambda}^{\uparrow}\left(d^{0}\right)^{2}}{E_{\lambda}^{0} \cos \vartheta^{0}}
$$

In Eq. (12) the spectral (reflected) radiance, $K_{\lambda}^{\uparrow}\left(\mathrm{W} \mathrm{m}^{-2}\right)$, and the extraterrestrial solar irradiance, $E_{\lambda}^{0}\left(\mathrm{~W} \mathrm{~m}^{-2}\right)$, are integrated values over the width of each spectral band $\lambda_{i} ; \vartheta^{0}$ and $d^{0}$ are the solar zenith angle and the sun-earth distance in Astronomical Units. When using atmospherically corrected surface reflectance values, the surface albedo can be calculated as (Menenti et al., 1989):

$$
\left.\alpha=\sum_{\lambda} w_{\lambda} \rho_{\lambda} \quad \lambda=1,2, \ldots, 5,\right)
$$

where the weighting factors $w_{\lambda}$ are given by:

$$
w_{\lambda}=\frac{E_{\lambda}^{0}}{\sum_{\lambda} E_{\lambda}^{0}}
$$

A list of weighting factors for different types of sensors is given in Table 4 .
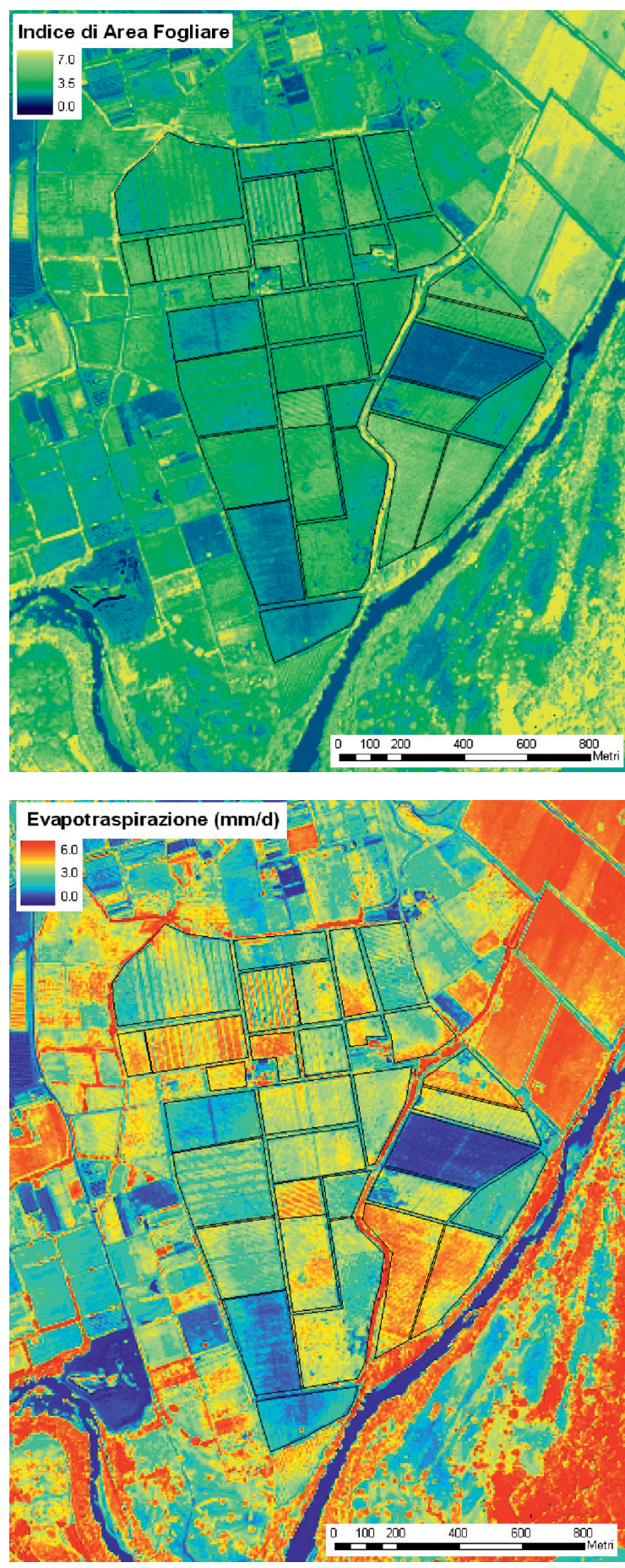

Figure 4. Maps of LAI and $E T_{p}$ derived from a Quickbird image acquired over the Sele plain by using the F.A.O.-56 analytical approach.

An example of application of the F.A.O.-56 analytical approach developed within the AQUATER project is shown in Figure 4, where the maps of LAI and $E T_{p}$ for an area in the Se- 
Table 4. Weighting coefficients for the calculation of albedo $\alpha$ by using Eq. (14) and atmospherically corrected surface reflectance.

\begin{tabular}{lcc|ccc}
\hline Sensor \& Band & $E_{\lambda}^{o}{ }_{\lambda} \mathrm{W} / \mathrm{m}^{2} \mu \mathrm{m}$ & $w_{\lambda}$ & Sensor/Band & $E_{\lambda}^{o} \mathrm{~W} / \mathrm{m}^{2} \mu \mathrm{m}$ & $w_{\lambda}$ \\
\hline Landsat 4-5 TM1 & 1957.0 & 0.2935 & ASTER1 & 1846.0 & 0.3625 \\
Landsat 4-5 TM2 & 1826.0 & 0.2738 & ASTER2 & 1555.0 & 0.3054 \\
Landsat 4-5 TM3 & 1554.0 & 0.2330 & ASTER3 & 1120.0 & 0.2200 \\
Landsat 4-5 TM4 & 1036.0 & 0.1554 & ASTER4 & 231.0 & 0.0454 \\
Landsat 4-5 TM5 & 215.0 & 0.0322 & ASTER5 & 79.0 & 0.0155 \\
Landsat 4-5 TM7 & 80.7 & 0.0121 & ASTER6 & 74.4 & 0.0146 \\
& & & ASTER7 & 70.5 & 0.0138 \\
Landsat 7 ETM1 & 1970.0 & 0.2930 & ASTER8 & 59.6 & 0.0117 \\
Landsat 7 ETM2 & 1843.0 & 0.2741 & ASTER9 & 56.3 & 0.0111 \\
Landsat 7 ETM3 & 1555.0 & 0.2313 & IKONOS 1 & $/$ & 0.2444 \\
Landsat 7 ETM4 & 1047.0 & 0.1557 & IKONOS 2 & $/$ & 0.3110 \\
Landsat 7 ETM5 & 227.1 & 0.0338 & IKONOS 3 & $/$ & 0.2204 \\
Landsat 7 ETM7 & 80.5 & 0.0120 & IKONOS 4 & $/$ & 0.2241 \\
IRS-C LISS III 1 & 1933.3 & 0.3912 & QuickBird 1 & $/$ & 0.2655 \\
IRS-C LISS III 2 & 1641.3 & 0.3321 & QuickBird 2 & $/$ & 0.3019 \\
IRS-C LISS III 3 & 1117.0 & 0.2260 & QuickBird 3 & $/$ & 0.1970 \\
IRS-C LISS III 4 & 250.6 & 0.0507 & QuickBird 4 & $/$ & 0.2356 \\
SPOT4-5 XS1 & 1851.0 & 0.3925 & & & \\
SPOT4-5 XS2 & 1586.0 & 0.3339 & & & \\
SPOT4-5 XS3 & 1054.0 & 0.2240 & & & \\
SPOT4-5 SWIR & 240.0 & 0.0496 & & &
\end{tabular}

le plain have been derived from atmospherically corrected reflectance acquired with Quickbird and processed by using Eqs. (8) through (14).

The extraction of quantitative parameters from E.O. images requires preliminary corrections for the geometrical rectification and the reduction of atmospheric effects on the reflectance detected at the sensor. The geometrical rectification is a semi-automatic process, which precision can be improved by using ground control points; the atmospheric correction is particularly needed in the visible and termal spectral regions, and it can be performed by using radiative transfer models with standardized vertical distribution of water vapours and aerosols. In many applications, it is appropriate to carry out at least a radiometric calibration, i.e. the conversion of raw digital number of the image pixels into "at sensor" radiance, namely the Top Of Atmosphere reflectance (TOA).

When a more complete radiometric information is available instead, i.e. by using TERRA-ASTER data or new generation of satellite with super-spectral capabilities, such as CHRIS Proba or the future ESA Sentinel-2 mission, it is possible to apply physically-based model of vegetation radiative transfer to estimate canopy albedo and LAI, without strong restricting assumptions as in the empirical approaches described above. A possibility is offered by a fast and robust inversion techniques based on the construction of a look up table (LUT) (Weiss et al., 2000) from the widespread SAIL model (Verhoef, 1984) combined with PROSPECT (Jacquemoud et al., 1990). This combined model takes into account the effect of soil background, the optical properties of the leaves, which are related to pigments and leaves water content. As such, diversely from Eqs. (9) through (14), an higher amount of spectral information is required to achieve a satisfactory level of accuracy in the results (Richter et al., 2008, 2009). A remarkable difference between the empirical methods and the physically-based PROSPECT +SAIL models is the possibility of taking into account the influence of illumination and observation geometry, without invoking the Lambertian assumption; furthermore, a preliminary parameters calibration is not needed in most cases, thus avoiding field data acquisition simultaneously to satellite acquisitions.

Simultaneous directional observations in the visible and near infrared regions have been made available from the experimental satellite 
PROBA with his Compact High Resolution Imaging Spectrometer (Tab. 1a; Barnsley et al., 2004). During 2003 and 2004, this satellite has been acquiring images over the agricultural site of Barrax (Spain); intensive field campaigns have been organised in coincidence of the satellite passes to exploit the unique and innovative hyper-spectral and multi-angular information content of CHRIS/PROBA imagery (http:// www.esa.int/esaCP/SEM6NFYO4HD_index_0.h tml). This data set has been extremely helpful to validate the inversion of radiative transfer models for LAI and other canopy parameters (D'Urso et al., 2009a). Results from model inversion have not only shown that the directional information content improves LAI and albedo estimation, but also that it is predominant on the spectral information, thus opening new perspective for future space-borne instruments with better capabilities for the characterization of surface reflectance anisotropy.

For operative applications it has been recently launched the WorldView-2 satellites, carrying a sensor capable of sub-metric spatial resolution and 8 spectral bands in the visible and infrared regions; thanks to its pointing capabilities, the repeat cycle of image acquisition is very short (3 days). This powerful combination of technical characteristics opens new perspectives for the applications of innovative methodologies of data analysis and interpretation, based on the mentioned physically based approach.

The F.A.O.-56 analytical approach described in this section has been validated by using independent measurements of evaporation fluxes obtained from micro-meteorological instrumentations during different field campaigns; experimental data acquired over corn and alfalfa plots under well-watered conditions showed an excellent 1:1 correlation between measured and estimated ET values derived from the inversion of cited models with broad-band spectral data (Fig. 5). Diversely, the $K_{c}$-NDVI has resulted in a consistent overestimation of crop water requirements $(+15 \%)$ in herbaceous crops i.e. corn and alfalfa (Vuolo et al., 2008).

\section{From research to operative applications}

The methodologies presented in this paper are ready for being transferred to operational ap- plications, thanks also to the availability of most innovative Information and Communication Technologies (I.C.T.).

The F.A.O.-56 approach for the calculation of CWRs from E.O. data has been implemented in an irrigation advisory service available both for irrigation associations and individual farmers in the Campania region since 2007. The information on E.O.-based CWRs is implemented in a tool for near-real-time services to support water management at two different levels: the irrigation associations (in Italy, Consortia); the individual farmers (D'Urso et al., 2009b). The key-information required by the first level of users is the total amount of crop water requirements in order to cope with the actual availability of water resources. The second level of information, addressed to farmers, consists basically of the maximum amount of water to be applied in each plot (consistently with the definition of CWR given above) during a time interval, typically 5-7 days.

The initial prototype, developed in the mentioned EU-funded projects DEMETER and PLEIADeS, has been further refined in the course of AQUATER, and implemented at industrial level by Ariespace s.r.l. Currently available high-resolution satellites (including SPOT) thanks to their constellation configuration and pointing capabilities permit an average temporal resolution of 5-7 days, which is very satisfactory for crop water requirements calculation at both district scale and farm scale. The service is operational since 2007 in four irrigation Consortia in the Campania region and it reaches about 300 farmers with a total extension of 3400 ha (for detailed information in Italian: http:// www.consulenzairrigua.it).

This level of service has required the development of semi-automatic procedures in order to elaborate $E T_{p}$ maps from E.O. data in the minimum possible time. Once the data are acquired by the satellite, i.e. at 10:00 a.m. day 1, the raw image is available via FTP within 12-36 hours at the processing center. The following processing steps are then applied: geometric correction (based on Ground Control Points), atmospheric correction, calculation of canopy parameters and CWRs. This processing is generally completed within $24 \mathrm{hrs}$ from image download. These products are then directly delivered to each farmer by using I.T. in two ways: 

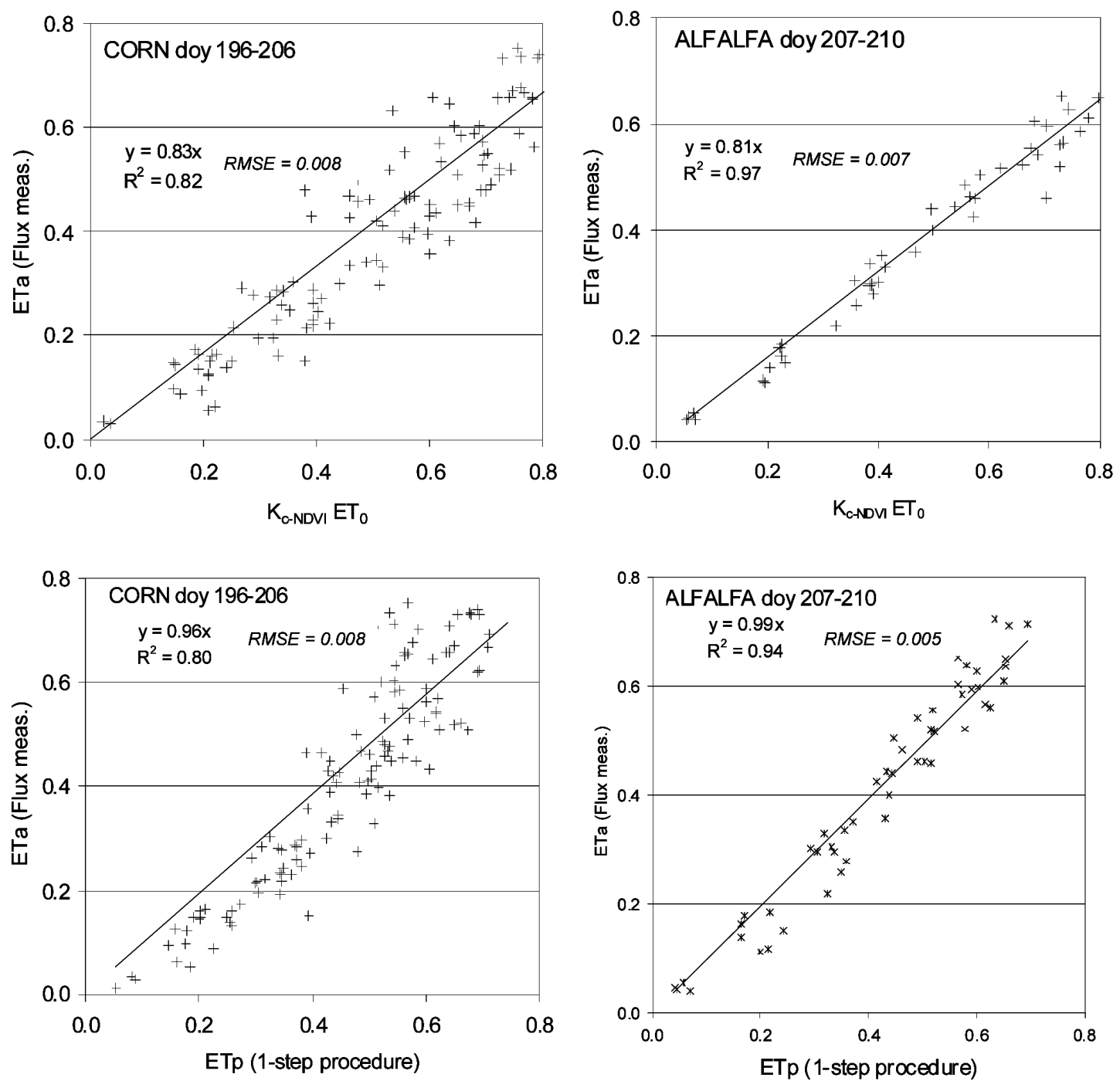

Figure 5. Comparison of vegetation indexes and F.A.O.-56 analytical approach made by using field spectral data and Eddy-covariance in well-irrigated corn and alfalfa fields.

(1) simple text report by using SMS; (2) standard report, by MMS and e-mail, including images of the fields in false colours combination (similar to Fig. 4) and a CWR map.

\section{Conclusions}

Current E.O. platforms have greatly improved both the quality and the revisit time in the visible and near infrared regions. The spatial resolution of $10 \mathrm{~m}$ or better is of great potentiality for all precision-agriculture practices. A similar process has not occurred for observation in the thermal range, in spite of the great progresses made in understanding the energy balance of vegetated surfaces.

From a qualitative assessment of land surface patterns, i.e. land-use and land-cover, the analysis of E.O. data in the visible and near infrared regions has evolved toward the quantitative estimation of land and vegetation parameters. The availability of new methodologies for interpreting observations has produced a sharp increase in the quality of information for monitoring crop development. This information is of great usefulness when combined with models describing mass exchanges in the soil-plant-atmosphere system. This level of knowledge - to- 
gether with an unprecedented combination of new technologies such as GIS and ICT - allows for the development of reliable "Decision Support" tools in irrigation management both at district and farm scales. DSS integrated with E.O. data have nowadays reached a stage of robustness which makes possible the transfer of these technologies to operative applications. With the reduction of costs for the acquisition of high resolution imageries, the implementation of operational services for irrigation advisory services based on E.O. is already economically beneficial in agricultural systems where irrigation fees are applied on a volume basis or in presence of energy costs for lifting. Where farmers find economical incentives to increase the irrigation efficiency, the technological transfer has already begun, with great potential for a more efficient utilisation of water resources in agricultural systems.

\section{Acknowledgments}

This work has been supported by Italian Ministry of Agriculture and Forestry Policies under contract n. 209/7393/05 (AQUATER Project) and by the European Community under its Sixth Framework Programme "PLEIADeS" (Participatory multi-Level EO-assisted tools for Irrigation water management and Agricultural Decision-Support - Project Contract Number 037095).

\section{References}

Acutis M., Perego A., Bernardoni E., Rinaldi M. 2010. AQUATER Software as a DSS for Irrigation Management in Semi-Arid Mediterranean Areas. Italian Journal of Agronomy, 5, 2:205-215.

Allen R.G, Pereira L.S., Raes D. and Smith M. 1998. Crop evapotranspiration - Guidelines for computing crop water requirements - FAO Irrigation and drainage paper 56, FAO, Rome.

Baret F., Guyot G. 1991. Potential and limits of vegetation indices from LAI and APAR assessment. Remote Sens. Environm., 35:161-173.

Barnsley M.J., Settle J.J., Cutter M., Lobb D., Teston F. 2004. The PROBA/CHRIS mission: A low-cost smallsat for hyperspectral, multiangle, observations of the earth surface and atmosphere; IEEE Trans. Geosci. Remote Sens., 42, 7:1512-1520.

Bastiaanssen W.G.M. 1995. Regionalization of surface flux densities and moisture indicators in composite terrain. PhD Thesis, Wageningen Agricultural University, $273 \mathrm{pp}$.

Bausch W.C., Neale C.M.U. 1987. Crop coefficients derived from reflected canopy radiation: a concept. Transactions American Soc. Agric. Engin., 30, 3:703-709.
Bausch W.C. 1995. Remote sensing of crop coefficients for improving the irrigation scheduling of corn. Agric. Water Manag., 27:55-68.

Braden H. 1985. Ein energiehaushalts- und verdunstungsmodell for wasser und stoffhaushaltsuntersuchungen landwirtschaftlich genutzer einzugsgebiete. Mittelung Deutsche Bodenkundliche Geselschaft, 42, 294-299.

Calera A., Martínez C., Meliá J. 2001. A procedure for Obtaining Green Plant Cover: Relation to NDVI in a Case of Study for Barley. International Journal of Remote Sensing, 22, 17:3357-3362.

Calera A., Osann A., Cuesta A., Montoro Rodríguez A., López Fuster P. 2005. Irrigation management from space: Towards user-friendly products. Irrigation and Drainage Systems, 19, 3-4:337-353.

Choudhury B.J., Ahmed N.U., Idso S.B., Reginato R.J., Daughtry C.S.T. 1994. Relations between evaporation coefficients and vegetation indices studied by model simulations. Remote Sens. Environ., 50:1-17.

Clevers J.G.P.W. 1989. The application of a weighted infrared-red vegetation index for estimating leaf area index by correcting for soil moisture. Remote Sens. Environm., 29:25-37.

Deering D.W. 1978. Rangeland reflectance characteristics measured by aircraft and spacecraft sensors. PhD Dissertation, Texas A \& M University, College Station, $338 \mathrm{pp}$.

Doorenbos J., Pruitt W.O. 1977. Guidelines for predicting crop water requirements. FAO Irrigation and Drainage Paper nr. 24, Rome, 144 pp.

D'Urso G. 2001. Simulation and Management of On-Demand Irrigation Systems: a combined agro-hydrological approach. PhD Dissertation, Wageningen University, ISBN 90-5808-399-3, 174 pp.

D’Urso G., Menenti M. 1995. Mapping crop coefficients in irrigated areas from Landsat TM images; Proceed. European Symposium on Satellite Remote Sensing II, Europto, Paris, sett.'95; SPIE, Intern. Soc. Optical Engineering, Bellingham (U.S.A.); Vol. 2585:41-47.

D’Urso G., Menenti M. 1996. Performance indicators for the statistical evaluation of digital image classifications. ISPRS J. Photogr. \& Rem. Sens., 51, 2:78-90.

D’Urso G., Calera Belmonte A. 2006. Operative approaches to determine crop water requirements from Earth Observation data: methodologies and applications. AIP conference proceedings 852: Earth Observation for Vegetation and Water Management, 14-25.

D’Urso G., Gomez S., Vuolo F., Dini L. 2009a. Estimation of land surface parameters through modeling inversion of Earth Observation optical data. In: Papajorgji P.J., Pardalos P.M. (eds.): Advances in Modeling Agricultural Systems, Springer Science, 317-338.

D’Urso G., D’Antonio A., Vuolo F., De Michele C. 2009b. The Irrigation Advisory Plan of Campania Region: from research to operational support for the Water Directive in Agriculture. In: Options Méditerranées, Serie A, 84:25-32. 
Estes J.E., Jensen J.R., Tinney L.R. 1978. Remote sensing of agricultural water demand information: a California study. Water Resour. Res., 14, 2:170-176.

FAO 1995. Use of remote sensing techniques in irrigation and drainage. Proceed. Expert Consultation FAO-Cemagref, Montpellier, Nov. 1993; Food and Agriculture Organis., Water Report, nr. 4, 201 pp.

Feddes R.A., Kabat P., van Bakel P.J.T., Bronswijk J.J.B., Halbertsma J. 1988. Modelling soil water dynamics in the unsaturated zone. State of the art. J. Hydrology, 100:69-111.

Huete A.R. 1988. A soil adjusted vegetation index (SAVI). Remote Sens. Environm., 25:295-309.

ICID-CIID 2000. Multilingual Technical Dictionary on Irrigation and Drainage. - CD Version September 2000, International Commission on Irrigation and Drainage, New Dehli.

Jackson R.D., Idso D.B., Reginato R.J., Pinter Jr.J.R. 1981. Canopy temperature as a crop water stress indicator. Water Resour. Res., 17:1133-1138.

Jacquemoud S., Baret F. 1990. PROSPECT: A model of leaf optical properties spectra. Remote Sensing of Environment, 34, 75-91.

Jensen M.E., Burman R.D., Allen R.G. 1990. Evapotranspiration and irrigation water requirements. ASCE Manual, no. 701.

Kelliher F.M., Leuning R., Raupach M.R., Schulze E.D. 1995. Maximum conductances for evaporation from global vegetation types. Agricultural Forest Meteorology, 73:1-16.

Kustas W.P., Norman J.M. 1996. Use of remote sensing for evapotranspiration monitoring over land-surfaces. Hydrological Sciences Journal, 41, 4:495-516.

Menenti M., Bastiaanssen W.G.M., van Eick D. 1989. Determinantion of surface hemispherical reflectance with Thematic Mapper data. Remote Sens. Environm., 28:327-337.

Menenti M., Ritchie J.C. 1994. Estimation of aerodynamic roughness of Walnut Gulch watershed with laser altimeter measurements. Water Resour. Res., 30, 5:1329-1337.

Monteith J.L., Unsworth M.H. 1990. Principles of Environmental Physics., E. Arnold Ed., London, 290 pp.

Pinty B., Verstraete M.M., Dickinson R.E. 1990. A physical model of the bidirectional reflectance of vegetation canopies. 2. Inversion and validation. Journal of Geophysical Research, 95:767-775.
Pinty B., Verstraete M.M. 1992. GEMI: A non-linear index to monitor global vegetation from satellites. Vegetatio, 101:15-20.

Price J.C. 1992. Estimating Leaf Area Index from remotely sensed data. Proc. IGARSS '92 (Houston), 1:1500-1502.

Richardson A.J., Wiegand C.L. 1977. Distinguishing vegetation from soil background information, Photogramm. Eng. Remote Sens., 43:1541-1552.

Richter K., Vuolo F., D’Urso G. 2008. Leaf area index and surface albedo estimation: comparative analysis from vegetation indexes to radiative transfer models. Proceed. IGARSS 2008, Boston, U.S.A.; III:736-739.

Richter K., Atzberger C., Vuolo F., Weihs P., D'Urso G. 2009. Experimental assessment of the Sentinel-2 band setting for RTM-based LAI retrieval of sugar beet and maize. Canad. J. Rem. Sens., 35, 3:230-247.

Ritchie J.T. 1972. A model for predicting evaporation from a row crop with incomplete cover. Water Resour. Res., 8, 5:1204-1213.

Santini A. 1992. Modelling water dynamics in the soilplant-atmosphere system for irrigation problems. Excerpta, n. 6, Milano (Italy).

Schultz G.A., Engman E.T. (eds.) 2000. Remote Sensing in Hydrology and Water Management. Springer-Verlag Inc., New York, U.S.A., 473 pp.

Stanghellini C., Bosma A.H., Gabriels P.C.J., Werkhoven C. 1990. The water consumption of agricultural crops: how crop coefficients are affected by crop geometry and microclimate. Acta Horticulturae, 278:509-515.

Szeicz G., Long I.F. 1969. Surface resistance of crop canopies. Water Resour. Res., 5, 3:622-633.

Tucker C.J. 1978. A comparison of satellite sensor bands for vegetation monitoring. Photogram. Engin. And Remote Sens., 44:1369-1379.

Verhoef W. 1984. Light scattering by leaf layers with the application to canopy reflectance modeling: the SAIL model. Remote Sens. Environm., 17:165-178.

Vuolo F., D’Urso G., Richter K., Prueger J., Kustas W. 2008. Physically-based methods for the estimation of crop water requirements from E.O. optical data. Proceed. IGARSS 2008, Boston, U.S.A., IV:275-278.

Weiss M., Baret F., Myneni R.B., Pragnère A., Knyazikhin Y. 2000. Investigation of a model inversion technique to estimate canopy biophysical variables from spectral and directional reflectance data. Agronomie, 20:3-22. 